\title{
VIEW OF CORPSE FOUND AT THE EXPLOSION SCENE
}

\author{
Andrey A. Medentsov \\ Department of Forensic Medical Examination (Volgograd) of branch No. 2 \\ "111 Main State Center of Forensic Medical and Criminalistic Examination" \\ of the Ministry of Defense of the Russian Federation, Volgograd, Russian Federation; \\ Volgograd State University, Volgograd, Russian Federation
}

\section{Ekaterina S. Azarova}

Volgograd State University, Volgograd, Russian Federation

\section{Vitaly A. Ruchkin}

Volgograd State University, Volgograd, Russian Federation

\begin{abstract}
Introduction: in the modern world, the level of international terrorism is constantly growing, with an increasing tendency for terrorists to use an impressive arsenal of weapons of destruction, which creates a real threat to the world community, for all countries without exception. The use of various types of explosive devices in public places streets, railway stations, and trains - is directed by terrorists to intimidate the population and create a serious threat to stability and security in society. Therefore, at the present stage, it is important to apply all previously developed methods and techniques, as well as to use new recommendations in order to improve the logistics of the law enforcement agencies. The involvement of specialists in conducting such an important investigative action as the inspection of the accident scene will contribute to an objective perception, a full study of the scene, the detection, recording and removal of various traces and other physical evidence in order to clarify the nature of the event. The purpose of the study: to determine the methods available to the investigator, providing the maximum possible information for further investigation of the crime. The objectives of the study: to describe the principles of modern tactics of conducting the accident scene observation; to clarify requirements and review the specifics of the inspection report of the explosion scene; to develop recommendations on the examination and recovery of the objects. Methods: the methodological framework is based on the methods of historicism, systematization, and comparative law. Results: the proposals were made to improve the interaction of the investigator with the forensic expert involved in the scene examination. Conclusions: as a result of the study, it is revealed that when the forensic examination of corpses or their fragments discovered at the accident scene when an explosive device was used, an approximate list of questions for the forensic expert is formed for the investigators. It is established that the use of the techniques available to the investigator $<$ provides the necessary information for further investigative actions.
\end{abstract}

Key words: inspection, the accident scene, criminalistics, investigative action, forensic examination.

Citation. Medentsov A.A., Azarova E.S., Ruchkin V.A. View of Corpse Found at the Explosion Scene. Legal Concept, 2020, vol. 19, no. 2, pp. 77-83. (in Russian). DOI: https://doi.org/10.15688/lc.jvolsu.2020.2.11

\section{ОСМОТР ТРУПА, ОБНАРУЖЕННОГО НА МЕСТЕ ВЗРЫВА}

\section{Андрей Альбертович Меденцов}

Отделение судебно-медицинской экспертизы (г. Волгоград) филиала № 2

«111 Главный государственный центр судебно-медицинских и криминалистических экспертиз» Министерства обороны Российской Федерации, г. Волгоград, Российская Федерация; Волгоградский государственный университет, г. Волгоград, Российская Федерация 


\title{
Екатерина Сергеевна Азарова
}

Волгоградский государственный университет, г. Волгоград, Российская Федерация

\section{Виталий Анатольевич Ручкин}

Волгоградский государственный университет, г. Волгоград, Российская Федерация

\begin{abstract}
Введение: в современном мире постоянно происходит рост масштабов международного терроризма с увеличением тенденции применения террористами внушительного арсенала средств поражения, что создает реальную угрозу мировому сообществу. Применение террористами различных видов взрывных устройств в публичных местах (на улицах, вокзалах, в поездах) направлено на устрашение населения, создание серьезной угрозы стабильности и безопасности в обществе. По этой причине на современном этапе большое значение имеет использование всех ранее разработанных методов и методик, а также новых рекомендаций ввиду усовершенствования материально-технического обеспечения правоохранительных органов. Привлечение специалистов для проведения такого важного следственного действия, как осмотр места происшествия, будет способствовать объективному восприятию, полному изучению обстановки места происшествия, обнаружению, фиксации и изъятию различных следов и других вещественных доказательств в целях выяснения характера произошедшего события. Цель исследования: определить методики, имеющиеся в распоряжении следователя, обеспечивающие получение максимально возможной информации для дальнейшего расследования преступления. Задачи исследования: охарактеризовать современные принципы тактики проведения осмотра места происшествия; уточнить требования и рассмотреть особенности оформления протокола осмотра места происшествия при взрывах; разработать рекомендации по исследованию и изъятию объектов. Методы: методологическую основу составляют методы историзма, системности, сравнительно-правовой. Результаты: сформированы предложения о совершенствовании взаимодействия следователя с привлеченным к осмотру места происшествия специалистом в области судебной медицины. Выводы: в результате исследования выявлено, что при направлении на судебно-медицинскую экспертизу обнаруженные трупы или их фрагменты на месте происшествия с применением взрывного устройства для следователей формируется примерный перечень вопросов к врачу- судебно-медицинскому эксперту. Установлено, что применение методик, имеющихся в распоряжении следователя, обеспечивает получение необходимой информации для дальнейших следственных действий.
\end{abstract}

Ключевые слова: осмотр, место происшествия, криминалистика, следственное действие, судебная экспертиза.

Цитирование. Меденцов А. А., Азарова Е. С., Ручкин В. А. Осмотр трупа, обнаруженного на месте взрыва // Legal Concept = Правовая парадигма. - 2020. - Т. 19, № 2. - C. 77-83. - DOI: https://doi.org/10.15688/ lc.jvolsu.2020.2.11

\section{Введение}

Применение террористами различных видов взрывных устройств в публичных местах (на улицах, вокзалах, в поездах) направлено на устрашение населения, создание серьезной угрозы стабильности и безопасности в обществе. По этой причине на современном этапе большое значение имеет использование всех ранее разработанных методов и методик, а также новых рекомендаций ввиду усовершенствования материально-технического обеспечения правоохранительных органов [5, с. 102]. Привлечение специалистов при проведении такого важного следственного действия, как осмотр места происшествия, будет способствовать объективному восприятию, полному изучению обстановки места происшествия, обнаружению, фиксации и изъятию различных следов и других вещественных доказательств в целях выяснения характера произошедшего события.

Качество и полнота проведенного осмотра места происшествия (далее - МП) при взрыве взрывных устройств зависит от многих факторов, а именно от степени подготовки, профессиональных навыков и знаний у следователя по расследованию данной категории преступлений. На основании этого следователь до осмотра МП должен хорошо себе представлять задачи, принципы и результаты данного следственного действия, что позволит в значительной степени обеспечить получение максимально возможной информации для дальнейшего расследования преступления. 
Даже незначительное промедление с осмотром места происшествия может привести не только к изменению обстановки, но и к невосполнимой утрате следов или иных вещественных доказательств [2, с. 30], что в значительной мере замедлит или даже затруднит ход расследования этой сложной категории преступлений.

\section{Принципы тактики проведения осмотра места происшествия}

При различных погодных условиях, в разные времена года следователь должен соблюдать основные принципы тактики проведения осмотра МП - своевременность и полноту, тем более, если объектами осмотра являются трупы потерпевших или их фрагменты. Осмотр следует начинать с данных объектов, особенно в случаях, когда неблагоприятные погодные условия (высокая или низкая температура окружающей среды, осадки различного характера и т. д.) могут привести к быстрым изменениям трупного материала, что в дальнейшем, как указывалось выше, может затруднить ход расследования. В соответствии с законом наружный осмотр трупа на месте его обнаружения обязательно проводится с участием врача-специалиста в области судебной медицины (ст. 180 УПК).

При взрыве применяемых различных взрывных устройств малого или значительного количества взрывчатых веществ (далее BВ) (тола, динамита и др.), как правило, на тело действуют физические факторы, которые возникают в ходе быстрого выделения огромного количества энергии. Повреждения от действия факторов взрыва носят различный характер: поверхностные - в виде ссадин и кровоподтеков; травматическая ампутация конечностей (отрывы периферических частей тела - пальцев, кистей, стоп) [1, с. 187]; наличие сочетанных повреждений; раневые каналы от наружных осколочных ранений в теле и конечностях носят слепой характер; наличие закрытых повреждений внутренних органов; баро-травма; раны на наружных покровах имеют различную форму и величину; наличие продуктов взрыва в области ран и по ходу раневых каналов (копоть, фрагменты взрывного устройства в виде частиц оболочки и взрыв- чатого вещества); следы термического и химического действия взрывных газов и фрагментов взрывного устройства в виде опаления волос на голове, термических ожогов тела и одежды. Данный характер повреждений зависит от множества факторов: от количества взрывчатого вещества во взрывном устройстве; вида взрывного устройства (наличия или отсутствия оболочки); наличия вторичных снарядов - различных металлических предметов; расстояния (дистанции), на котором находился потерпевший от эпицентра взрыва; положение и поза потерпевшего в пространстве в момент взрыва (какой поверхностью тела был обращен потерпевший к эпицентру взрыва, был расположен стоя, лежа или сидя) - большее количество повреждений обычно локализуется на стороне тела потерпевшего, обращенной к эпицентру взрыва; наличие или отсутствия преграды между потерпевшим и эпицентром взрыва; количество и качество одежды; особенности рельефа места взрыва (открытое пространство, замкнутое пространство) и т. д.

При наличии на месте происшествия трупов потерпевших или их частей осмотр следует начинать с них, особенно в случаях, когда неблагоприятные погодные условия угрожают быстрыми изменениями трупного материала. Процедура должна производиться с обязательным участием специалиста в области судебной медицины.

При взрыве взрывных устройств на близкой дистанции (контактной) на одежде и наружных кожных покровах будут иметь место следы действия всех факторов взрыва - термические (ожоги, опаление волос, наличие копоти), механические (повреждение тканей, отрывы конечностей, перелом костей скелета и внутренних органов) и химические - образование карбоксигемоглобина в проекции поврежденных наружных покровов. При взрывах на относительно близкой дистанции отмечаются преимущественное поражение внутренних органов в виде разрывов, наличие осколочных ранений. Отсутствуют повреждения от действия термических и химических факторов. При взрывах на неблизкой дистанции имеются только осколочные ранения.

Чтобы в ходе проведения осмотра МП не упустить и, возможно, больше выявить све- 
дений, на месте взрыва при обнаружении трупа (трупов) следователю необходимо провести следственные действия с участием врача - судебно-медицинского эксперта в следующей последовательности с соблюдением основных принципов осмотра МП:

1) с помощью фотоаппарата, видеокамеры (в закрытых помещениях), а также при наличии радиоуправляемого квадрокоптера с зафиксированной на нем камерой (на открытом пространстве) производится обзорная и детальная фото-, видеосъемка места взрыва, мест расположения трупа (трупов) или их фрагментов с учетом локализации эпицентра взрыва. Устанавливаются и фиксируются подробным образом поза трупа и его положение относительно окружающих его неподвижных предметов, для этого делают съемку сверху и по диагонали. Уместно с целью включения всех необходимых объектов в кадр проводить фотофиксацию с помощью панорамной съемки. Обнаруженные повреждения на одежде, различных участках тела, а также особые приметы и анатомические особенности трупа фиксируются масштабным способом;

2) с помощью современных методов и применения лазерных измерительных приборов точно определяется месторасположение трупов и их фрагментов по отношению к окружающим ближайшим неподвижным предметам (ориентирам) и от эпицентра взрыва. С применением компаса устанавливается местонахождение трупа или его фрагментов относительно частей света.

\section{Особенности оформления протокола осмотра места происшествия}

Осмотр и подробное описание предметов одежды, расположенной на трупе, включает в себя обнаружение повреждений в виде дефекта сквозного характера, разрывов, опаления, ожогов и наложений копоти на ткани. Данные изменения фиксируются с помощью фото- или видеосъемки. При повреждении одежды в виде отрыва устанавливается ее тождество с другими фрагментами и расположение по отношению к ориентирам и месту взрыва.

Подробно по схеме фиксируются в протоколе осмотра МП все обнаруженные повреждения на трупе (трупах) или их фрагмен- тах: локализация, форма, размеры, наличие осаднения в проекции краев ран, наличие и направление раневых каналов и их содержимое, травматическая ампутация конечностей (на каком уровне конечности) [3, с. 8]. Все повреждения фиксируются посредством фото- и видеосъемки с применением масштабирования.

При исследовании повреждений необходимо тщательно разделить их на группы по комплексу наружных признаков:

а) повреждения, образовавшиеся от действия взрывного устройства [осколочные ранения, вызванные разлетом частей (оболочки) разрушенного взрывного устройства)] - от поверхностных до глубоких ранений;

б) повреждения, образовавшиеся от заложенных во взрывное устройство металлических предметов (иглы, стержни, гвозди, шарики, нарезка проволоки, гайки, болты и т. д.);

в) повреждения, образовавшиеся в результате прямой тупой травмы: при падениях пострадавших в результате воздействия ударной волны и удара о твердые предметы, а также в результате падения на пострадавших разрушенных в процессе взрыва строительных конструкций;

г) повреждения от действия вторичных снарядов, к которым следует отнести осколки различных преград и различных предметов, которые могут находится рядом с потерпевшим.

Обнаруженные следы от действия термических и химических факторов на теле погибшего фиксируются по принципу указания локализации, степени и глубины повреждений [4, с. 36]; фиксируются следы от химического действия взрывных газов - образование карбоксигемоглобина, мет- и сульфгемоглобина, алое окрашивание поврежденных тканей.

В ходе осмотра МП следователь должен принять все меры по обнаружению, исследованию, фиксации и изъятию объектов: осколков оболочки, деталей взрывного устройства, поврежденных и неповрежденных частиц взрывчатого вещества в ткани, складках предметов одежды, между одеждой и телом пострадавшего, обуви и трупе для последующего исследования в специальных криминалистических лабораториях и специалистами по вооружению [6, с. 107]. 
Ввиду того что некоторые объекты (сгоревшие и несгоревшие частицы ВВ, мелкие по размерам осколки и фрагменты взрывного устройства, вторичные снаряды) могут быть не зафиксированы на одежде, наружных кожных покровах трупа, для сохранения их целесообразно изъять. Извлечение данных объектов можно произвести с помощью поскабливания скальпелем либо легким поколачиванием изнутри наружу по ткани над листком бумаги.

В некоторых случаях с целью предотвращения утраты при транспортировке трупов в бюро СМЭ необнаруженных объектов в ходе осмотра можно произвести изъятие одежды на месте МП либо поместить труп в одежде в герметичный пакет из ткани или полиэтилена до его транспортировки. Данные мероприятия позволят сохранить все объекты для установления типа взрывного устройства, положения потерпевшего по отношению к эпицентру взрыва, химического состава ВВ и т. д.

В ходе осмотра трупа (трупов) или их фрагментов на МП категорически запрещается проводить зондирование и другие действия в проекции всех имеющихся повреждений, так как данные действия могут повлечь за собой различные неблагоприятные последствия: изменение первоначального вида или свойств повреждений. Категорически запрещено контактировать с повреждениями с целью удаления крови, данные действия могут привести к невосполнимой утрате важных вещественных доказательств - сгоревшие и несгоревшие порошинки, наложения копоти, мелкие фрагменты взрывного устройства.

Фрагменты предметов одежды, которые были обнаружены вне тел погибших, также изымаются, упаковываются в отдельные пакеты с указанием соответствующей надписи. Данные объекты позволят при дальнейшем их исследовании и сопоставлении с другими объектами идентифицировать личность, расположение ее по отношению к эпицентру взрыва и т. д.

В ходе осмотра МП привлеченный специалист в области судебной медицины выступает в качестве помощника, консультанта следователя, работая в соответствии с указаниями и под его руководством. В ходе осмотра МП специалист обращает внимание следова- теля на все особенности, дает пояснения своим действиям и помогает в оформлении протокола осмотра МП при взрывной травме.

\section{Выводы}

Таким образом, в протоколе осмотра МП специалистом указываются: положение трупа (трупов), их фрагментов по отношению к неподвижным предметам (ориентирам) и к установленному эпицентру взрыва; поза трупа; предметы, находящиеся на трупе или под ним; состояние и положение предметов одежды и обуви на трупе; наличие на поверхности и между слоями одежды свободно лежащих осколков и компонентов взрывного устройства, сгоревших и несгоревших частиц ВВ; локализация и характер повреждений на одежде трупа; указываются антропологические данные трупа, особые приметы на нем; указывается степень выраженности посмертных изменений; локализация и вид повреждений на теле трупа по схеме их описания, желательно с разделением их на группы по виду травмы.

При направлении на судебно-медицинскую экспертизу обнаруженные трупы или их фрагменты на месте происшествия при применении взрывного устройства следователем формируются вопросы, которые позволят в полной мере установить обстоятельства события.

Примерный перечень вопросов для врача - судебно-медицинского эксперта:

1. Какова причина и давность наступления смерти?

2. Какие повреждения имеются на теле погибшего, какова их локализация, количество, механизм образования и характер?

3. Какие повреждения на теле погибшего причинены в результате взрыва, их локализация, количество и характер? Какими факторами взрыва причинены данные повреждения? Имеются ли в проекции повреждений признаки, указывающие на вид применяемого взрывного устройства?

4. Какие повреждения на теле пострадавшего причинены не от действия факторов взрыва? Какова их локализация, количество, механизм образования и характер?

5. Какие повреждения, обнаруженные на трупе, нанесены прижизненно, а какие посмертно? 
6. Взрывом какого устройства (вид взрывного устройства) могли быть причинены повреждения? Каковы его мощность и конструктивные особенности?

7. На каком расстоянии, в каком положении и позе от эпицентра взрыва находился пострадавший?

8. Каково было взаимное расположение взрывного устройства и тела пострадавшего в момент взрыва?

9. Имеются ли в проекции наружных повреждений, по ходу раневых каналов инородные предметы, если да, то какие?

10. Имеются ли признаки в повреждениях, указывающие на наличие преграды в момент взрыва между телом пострадавшего и взрывным устройством?

Применение всех методов и методик, имеющихся в распоряжении следователя, привлечение различных специалистов, в том числе специалиста в области судебной медицины, с соблюдением всех основных принципов осмотра места происшествия, позволит уже в ходе проведения следственного действия - осмотра места происшествия обеспечить получение максимально возможной информации для дальнейшего расследования преступления.

\section{СПИСОК ЛИТЕРАТУРЫ}

1. Антонов, В. В. Обнаружение и исследование следов взрывных устройств / В. В. Антонов // Евразийский юридический журнал. - 2017. № 6. - С. 186-188.

2. Валеев, А. Х. Осмотр места взрыва при расследовании террористического акта / А. Х. Валеев // Вестник Восточно-Сибирского института Министерства внутренних дел России. - 2017. - № 3. C. 28-32.

3. Воротникова, Е. В. Осмотр трупа на месте его обнаружения / Е. В. Воротникова // Концепт. 2015. - № 3. - C. 6-10.

4. Ешенгалиев, А. Т. Производство осмотра места происшествия при расследовании преступлений, связанных с использованием взрывных устройств / А. Т. Ешенгалиев // Научный вестник Вол- гоградского филиала РАНХиГС. Серия: Юриспруденция. - 2018. - № 2. - С. 34-37.

5. Национальная безопасность России: контроверзы общества и государства / П. П. Фантров [и др.]. - Волгоград : Изд-во ВолГУ, 2019. - 190 с.

6. Пироженков, С. А. Особенности производства осмотра трупа на месте его обнаружения / С. А. Пироженков, Д. О. Серебров // Юридическая наука и практика: Вестник Нижегородской академии МВД России. -2012. -№ 18. - С. 104-109.

\section{REFERENCES}

1. Antonov V.V. Obnaruzhenie i issledovanie sledov vzryvnykh ustroystv [Detection and Investigation of Traces of Explosive Devices]. Evraziyskiy yuridicheskiy zhurnal [Eurasian Law Journal], 2017, no. 6, pp. 186-188.

2. Valeev A.H. Osmotr mesta vzryva pri rassledovanii terroristicheskogo akta [Inspection of the Place of the Explosion During the Investigation of the Terrorist Act]. Vestnik Vostochno-Sibirskogo instituta Ministerstva vnutrennikh del Rossii [Bulletin of East Siberian Institute of Ministry of Internal Affairs of Russia], 2017, no. 3, pp. 28-32.

3. Vorotnikokova E.V. Osmotr trupa na meste ego obnaruzheniya [Inspection of the Corpse at the Place of Its Discovery]. Kontsept [Concept], 2015, no. 3, pp. 6-10.

4. Eshengaliev A.T. Proizvodstvo osmotra mesta proisshestviya pri rassledovanii prestupleniy, svyazannykh $\mathrm{s}$ ispolzovaniem vzryvnykh ustroystv [Inspection of the Scene During the Investigation of Crimes Related to the Use of Explosive Devices]. Nauchnyy vestnik Volgogradskogo filiala RANHiGS. Seriya: Yurisprudenciya [Scientific Bulletin of Volgograd branch ofRANEPA. Series: Law], 2018, no. 2, pp. 34-37.

5. Fantrov P.P., Guhl V., Solovyova N.A., Shinkaruk V.M. Natsionalnaya bezopasnost Rossii: kontroverzy obshchestva i gosudarstva [National Security of Russia: Controversy of Society and the State]. Volgograd, 2019. 190 p.

6. Pirozhenkov S.A., Serebrov D.O. Osobennosti proizvodstva osmotra trupa na meste ego obnaruzheniya [Features of the Inspection of a Corpse at the Place of its Discovery]. Yuridicheskaya nauka i praktika: Vestnik Nizhegorodskoy akademii MVD Rossii [Legal Science and Practice: Bulletin of the Nizhny Novgorod Academy of the Ministry of Internal Affairs of Russia], 2012, no. 18, pp. 104-109. 


\section{Information About the Authors}

Andrey A. Medentsov, Candidate of Sciences (Medicine), Head of the Department of Forensic Medical Examination (Volgograd) of branch No. 2 "111 Main State Center of Forensic Medical and Criminalistic Examination" of the Ministry of Defense of the Russian Federation, Rokossovskogo St., 117, 400087 Volgograd, Russian Federation; Associate Professor, Department of Criminal Procedure and Criminalistics, Volgograd State University, Prosp. Universitetsky, 100, 400062 Volgograd, Russian Federation, vlg.fil2@bk.ru, https://orcid.org/0000-0003-4327-5074

Ekaterina S. Azarova, Candidate of Sciences (Jurisprudence), Associate Professor, Department of Criminal Procedure and Criminalistics, Volgograd State University, Prosp. Universitetsky, 100, 400062 Volgograd, Russian Federation, aes130804@yandex.ru, https://orcid.org/0000-0001-5130-1653

Vitaly A. Ruchkin, Doctor of Sciences (Jurisprudence), Professor, Head of the Department of Forensic Science, Volgograd State University, Prosp. Universitetsky, 100, 400062 Volgograd, Russian Federation, v.ruchkin@yandex.ru, https://orcid.org/0000-0003-3891-146X

\section{Информация об авторах}

Андрей Альбертович Меденцов, кандидат медицинских наук, заведующий отделением судебно-медицинской экспертизы (г. Волгоград) филиала № 2 «111 Главный государственный центр судебно-медицинских и криминалистических экспертиз» Министерства обороны Российской Федерации, ул. Рокоссовского, 117, 400087 г. Волгоград, Российская Федерация; доцент кафедры уголовного процесса и криминалистики, Волгоградский государственный университет, просп. Университетский, 100, 400062 г. Волгоград, Российская Федерация, vlg.fil2@bk.ru, https://orcid.org/0000-0003-4327-5074

Екатерина Сергеевна Азарова, кандидат юридических наук, доцент кафедры уголовного процесса и криминалистики, Волгоградский государственный университет, просп. Университетский, 100, 400062 г. Волгоград, Российская Федерация, aes130804@yandex.ru, https://orcid.org/0000-0001-5130-1653

Виталий Анатольевич Ручкин, доктор юридических наук, профессор, заведующий кафедрой судебной экспертизы, Волгоградский государственный университет, просп. Университетский, 100, 400062 г. Волгоград, Российская Федерация, v.ruchkin@yandex.ru, https://orcid.org/0000-0003-3891-146X 